\title{
Risk targeting in seismic design codes: The state of the art, outstanding issues and possible paths forward
}

John Douglas - Chancellor's Fellow (Lecturer), PhD, University of Strathclyde, Department of Civil and Environmental Engineering, Glasgow, UK e-mail: john.douglas@,strath.ac.uk

Athanasios Gkimprixis - $\mathrm{PhD}$ student, MSc, University of Strathclyde, Department of Civil and Environmental Engineering, Glasgow, UK e-mail: athanasios.gkimprixis@strath.ac.uk

\begin{abstract}
Over the past decade there have been various studies on the development of seismic design maps using the principle of "risk-targeting". The basis of these studies is the calculation of the seismic risk by convolution of a seismic hazard curve for a given location (derived using probabilistic seismic hazard analysis) with a fragility curve for a code-designed structure (ideally derived from structural modelling). The ground-motion level that the structure is designed for is chosen so that the structure has a pre-defined probability of achieving a certain performance level (e.g. non-collapse). At present seismic design maps developed using this approach are only widely applied in practice in the US but studies have also been conducted on a national basis for France, Romania, Canada and Indonesia, as well as for the whole of Europe using the European Seismic Hazard Model.

This short article presents a review of the state of the art of this technique, highlighting efforts to constrain better some of the input parameters. In addition, we discuss the difficulties of applying this method in practice as well as possible paths forward, including an empirical method to estimate an upper bound for the acceptable collapse and yield risk.
\end{abstract}

Keywords: seismic hazard, earthquake engineering, fragility curves, risk targeting, design, acceptable risk

\section{Introduction}

Current seismic building codes (e.g. Eurocode 8), based on results from a probabilistic seismic hazard analysis (PSHA), generally adopt a constant hazard approach to define the ground motions used for design. In other words, the peak ground acceleration (PGA, or other intensity measure, IM, e.g. spectral acceleration) used for design in one location has the same probability of being exceeded in a given year as the design PGA in another location. Often this annual probability is $1 / 475=0.0021$ (equivalent to $10 \%$ in 50 years or a return period of 475 years assuming a Poisson process). Ten years ago, Luco et al. (2007) proposed a new approach that targets a constant risk level across a territory. This has three principal advantages over the use of design levels defined in the traditional way: transparency, a uniform risk level across a territory and the ability to compare (and ideally control) risk for different types of hazard (e.g. earthquake and wind). It does come, however, with the disadvantage of making more choices explicit, rather than implicitly assumed because of convention (e.g. the choice of 475 years as the design return period).

The procedure of Luco et al. (2007), although often using different input parameters (see below), has been applied to France (Douglas et al., 2013), Romania (Vacareanu et al., 2017), Indonesia (SNI, 2012), Canada (Allen et al., 2015) and at a European scale (Silva et al., 2016), as well as forming the basis of the current US seismic design code (ASCE, 2010). Despite its numerous attractions (see above) and the fact that it is a relatively simple procedure to implement, there are a number of outstanding issues. For example, Douglas et al. (2013) note that the collapse probabilities targeted by Luco et al. (2007) appear to be at least an order of magnitude too high when compared with observed damage in previous earthquakes (also see Section 3.1 of this article). 
The next section presents an overview of the risk targeting approach and discusses previous choices of the critical input parameters. Section 3 highlights the outstanding problems and some potential solutions, which are currently being investigated by the authors.

\section{Method and required inputs to risk targeting}

The risk of collapse (or other level of structural damage) of a building at a given site from earthquake shaking can be estimated by convolving the seismic hazard curve, expressing the probability of different levels of ground motion, with the fragility curve, expressing the probability of collapse given these ground motions (e.g. Kennedy, 2011). This so-called "risk integral" forms the basis of the risk-targeting approach. For this approach there needs to be a link between the design acceleration and the fragility curve used to compute the risk of collapse. For a standard fragility curve based on the lognormal distribution, a single point on this curve (if the standard deviation is fixed) is required to define the building's fragility completely. A convenient choice is to use the design IM and the corresponding probability of a building attaining the considered damage state when subjected to that IM.

The general procedure for finding the design value for the considered IM (e.g. PGA) is shown in Fig. 1. The key input parameters, using the nomenclature of Douglas et al. (2013), are: $\beta$ (the standard deviation of the fragility curve assuming a lognormal distribution), $X$ (the probability of collapse at the design IM) and Y (the targeted annual probability of collapse). Seismic design codes generally do not report these values and hence assessing them has been the focus of considerable efforts over the past decade (see following section).

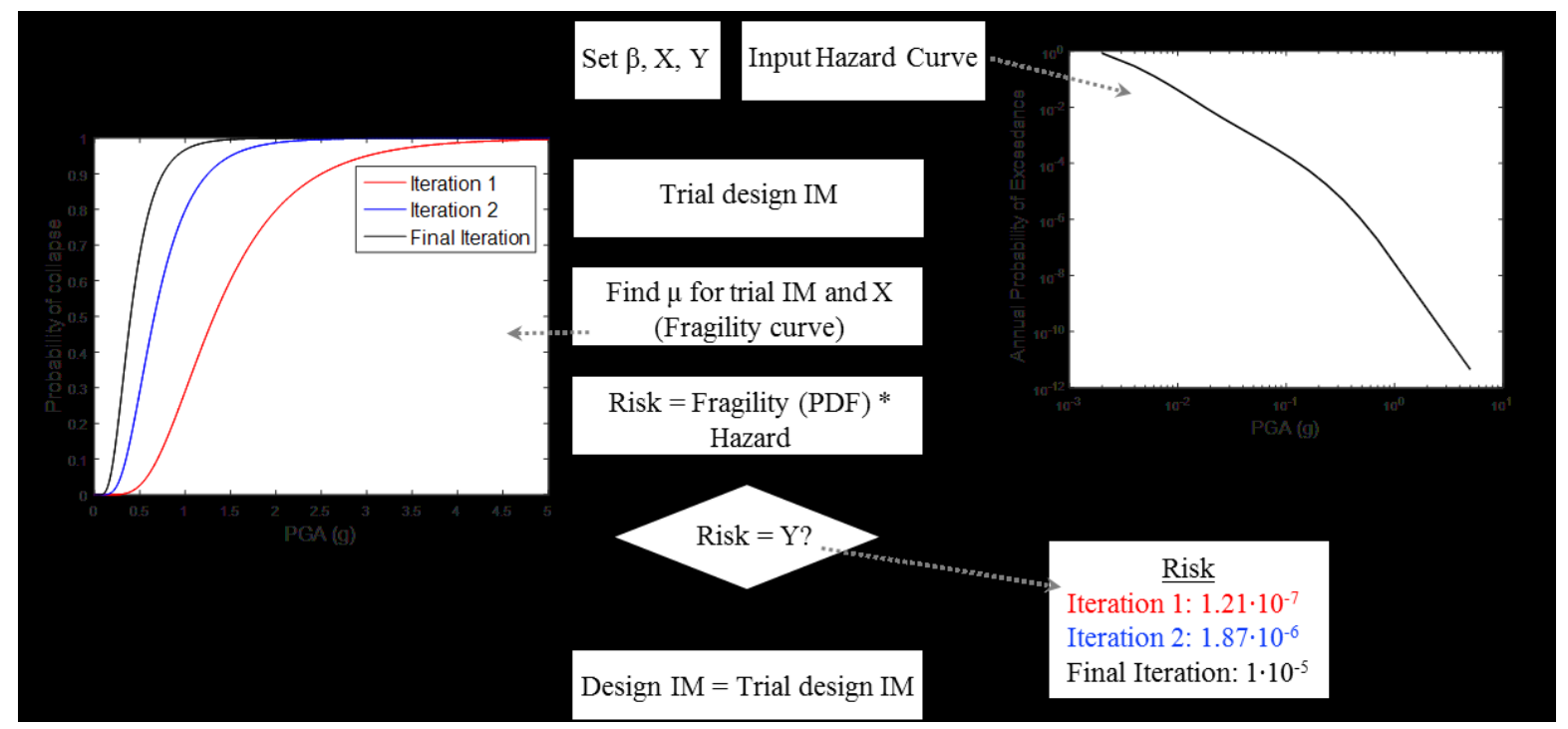

Fig. 1 - Flowchart of the method to find risk-targeted design parameters. $\mu$ is the mean of the fragility curve assuming a lognormal distribution.

There is a closed-form solution for the risk given a hazard curve expressed as a power law and a lognormal fragility curve (e.g. Kennedy, 2011), which can be used to understand the influence of different parameters on the design IM. For typical hazard curves, however, an iterative technique is required to determine the design IM (Fig. 1). We have found that a bisection method, which bounds the targeted risk from above and below until convergence to a given tolerance, is the best approach. To compute the convolution, numerical 
integration of the derivative of the fragility curve with the hazard curve using the trapezium rule works well.

The seismic hazard curve used within the calculation needs to be defined down to potentially very low probabilities of exceedance because the probabilities of collapse (or another damage state) defined by the fragility function are often far from one for large accelerations. This means that the hazard curve may need extrapolation, for which the power-law expression (based on the IMs for the smallest calculated probabilities) works well for most examples tested to date. We validated our algorithm by comparing our results with those from the Risk-Targeted Ground Motion Calculator available on the USGS website (https://earthquake.usgs.gov/hazards/designmaps/rtgm.php).

\subsection{The state of the art}

A summary from the literature of the three key inputs to the procedure is given in this section (we are assuming that the seismic hazard curve has been correctly defined by a recent PSHA for a wide range of probabilities of exceedance and that lognormal fragility curves are used).

ASCE (2005) provides design criteria for nuclear power plants and critical facilities based on a risk-targeting framework. The targeted risk ranges from $10^{-5}$ to $10^{-4}$, while for lower design categories values up to $10^{-3}$ are given in Braverman et al. (2007). To comply with the code, a nuclear plant must have a smaller than $1 \%$ chance of unacceptable performance for the design IM and less than 10\% for 1.5 times the design IM.

Kennedy (2011) comments on the ASCE (2005) approach and implements it for 28 US nuclear plants. With a $\beta$ in the range 0.3 to 0.6 , the Seismic Core Damage Frequencies (SCDFs) are between $6 \cdot 10^{-7}$ and $6 \cdot 10^{-6}$. Based on this, the United States Nuclear Regulatory Commission (2007) has set a target SCDF of $10^{-5}$.

Luco et al. (2007) use generic fragility curves with $\beta=0.8$. They assume a probability of collapse of $10 \%$ under the ground motion corresponding to a 2,475-year return period. The ATC-63 project initially proposed this value after analysing buildings designed with ASCE 7-05. Luco et al. (2007) find that the 2003 NEHRP design ground motions led to nonuniform risk across US territory. By targeting the average collapse probability in 50 years, which they found to be around 1\%, Luco et al. (2007) calculated new design ground motions with ratios of 0.7 to 1.15 of the 2003 NEHRP design ground motions.

The results of that report were considered for the ASCE 7-10 and 2009 NEHRP Provisions. The latter propose the convolution of a hazard curve with a fragility curve with $\beta=0.8$ (decreased to 0.6 in ASCE 7-10), $X=0.1$ and a target probability of collapse of $1 \%$ in 50 years. Liel et al. (2015) comment on ASCE 7-10 and suggest modifications to consider subduction earthquakes and near-fault effects. With the same $X$ and $\beta$ as in the regulation, the probability of collapse in 50 years varied from $0.21 \%$ to $0.62 \%$, for areas affected by subduction earthquakes, while at near-fault sites, the risk was much higher, reaching in some cases $6 \%$.

Allen et al. (2015) comment on the implementation of risk-targeting in Canada for future versions of its National Building Code (NBCC). For comparison, ground motion values derived from the risk-targeting approach of Luco et al. (2007) are divided with those proposed in 2015 NBCC (for a 2\%-in-50-year exceedance probability). The resulting risk 
coefficients for spectral accelerations at $1.0 \mathrm{~s}$ are between 0.84 and 1.00 in southwest Canada.

In Goulet et al. (2007) the collapse probabilities for a four-storey reinforced-concrete (RC) frame under the $2 \%$-in-50-year ground motion were calculated as between $0 \%$ and $2 \%$; after considering structural uncertainties the values increased to $2 \%$ to $7 \%$. They also found a variation of $\mathrm{Y}$ between $0.1 \cdot 10^{-4}$ and $0.5 \cdot 10^{-4}$ and between $0.4 \cdot 10^{-4}$ and $1.4 \cdot 10^{-4}$, when they considered structural uncertainties.

Fajfar and Dolšek (2012) examined a three-storey RC building with no provisions for earthquake resistance. They found an annual probability of collapse equal to $0.65 \cdot 10^{-2}$. When designed with Eurocode $8(\mathrm{CEN}, 2004 \mathrm{~b})$, this risk reduced to $2.22 \cdot 10^{-4}$ and to $2.7 \cdot 10^{-}$ ${ }^{4}$ when they accounted for epistemic uncertainties.

Ramirez et al. (2012) examine 30 buildings designed using the 2003 International Building Code (IBC) together with the ASCE provisions. They find the probabilities of collapse at the design PGA to be in the range $0.4 \%$ to $4.2 \%$ for these buildings.

Douglas et al. (2013) try to avoid significant changes in the existing design ground motions for France, which correspond to a 475-year return period. Considering previous studies, as well as the results of some sensitivity analyses, they finally choose $\beta=0.5$ and $X=Y=10^{-5}$. Under these assumptions, the estimated risk-targeted design PGAs are not very different from the values proposed by the current French code.

Ulrich et al. (2014a) present fragility curves for three-storey RC buildings designed according to Eurocodes 2 and 8 (CEN 2004a, 2004b) for different levels of design PGA, $\mathrm{ag}_{\mathrm{g}}$. They find yielding probabilities between 0.14 (for $\mathrm{ag}_{\mathrm{g}}=0.07 \mathrm{~g}$ ) and 0.85 (for $\mathrm{a}_{\mathrm{g}}=0.3 \mathrm{~g}$ ) and in the range $1.7 \cdot 10^{-7}(\mathrm{ag}=0.07 \mathrm{~g})$ to $1.0 \cdot 10^{-5}(\mathrm{ag}=0.3 \mathrm{~g})$ for the probabilities of collapse at the design PGA.

In Martins et al. (2015) fragility curves are also derived, firstly considering the spectral acceleration at the fundamental period of vibration $\mathrm{S}_{\mathrm{a}}\left(\mathrm{T}_{1}\right)$. This results in $\beta$ ranging from 0.35 to 0.45 , which increased up to 0.8 when they used PGA instead. For a three-storey RC building, they found the $\mathrm{X}$ to be equal to $5.20 \cdot 10^{-3}$ and $2.21 \cdot 10^{-2}$ for design accelerations of 0.2 and $0.4 \mathrm{~g}$, respectively, which change to $3.95 \cdot 10^{-3}$ and $5.57 \cdot 10^{-2}$ for a five-storey RC building. Then, using $\mathrm{S}_{\mathrm{a}}\left(\mathrm{T}_{1}\right)$ as the IM, the annual probabilities of collapse for the threestorey buildings were $9.50 \cdot 10^{-5}, 1.67 \cdot 10^{-5}$ and $1.07 \cdot 10^{-5}$, and for the five-storey buildings $1.78 \cdot 10^{-4}, 7.34 \cdot 10^{-5}$ and $2.97 \cdot 10^{-5}$, for design accelerations of $0.0 \mathrm{~g}, 0.2 \mathrm{~g}$ and $0.4 \mathrm{~g}$, respectively.

Likewise, the annual rates of collapse for the Italian territory are investigated by Iervolino et al. (2017). The current version of the Italian seismic code was used for the design of regular three-, six-, and nine-story RC buildings for two soil conditions. The results of their analyses indicate that annual collapse risk for code-conforming RC structures is between $10^{-5}$ and $2.02 \cdot 10^{-4}$. For the case of one-storey precast RC structures (also designed with the seismic code) $\mathrm{Y}$ values are found between $10^{-5}$ and $6.35 \cdot 10^{-3}$. The reader is referred to RELUIS and EUCENTRE (2014-2018) for details of this ongoing project.

Silva et al. (2016) study the fragility curves derived by the European project Syner-G and find an average value of $\beta=0.5$, which they consider as a lower bound. Assuming a $10 \%$ probability of collapse at the 2,475-year ground motion and the hazard curves derived by 
the European project SHARE (www.share-eu.org), for two values of $\beta$ (0.6 and 0.8 ) they find a probability of collapse at the 475-year design acceleration ranging from $10^{-3}$ to $10^{-2}$. Choosing then a value of $X=10^{-3}$ and $Y=5.0 \cdot 10^{-5}$ (by relating the risk of collapse to human losses), they propose new design maps for Europe.

Following a different approach, Tsang and Wenzel (2016) firstly define an acceptable fatality risk. Based on a literature review they choose a value of $10^{-6}$ for the acceptable annual fatality rate. They then estimate the corresponding limit for the targeted annual risk of complete structural damage as roughly $10^{-4}$. For a different limit state, the annual risk of "Real collapse" falls within the range $6 \cdot 10^{-6}$ to $8 \cdot 10^{-6}$.

Tsang et al. (2017) investigate buildings with precast RC columns designed using the risktargeted ground motions (MCER) proposed in IBC-2012 and ASCE/SEI 7-10. Theoretically, a $10 \%$ probability of collapse under the $\mathrm{MCE}_{\mathrm{R}}$ in 50 years is expected. They estimate, however, probabilities that are in every case lower than $10 \%$ (a maximum of $6.1 \%$ was found). In addition, the average annual collapse risk was estimated as $2.5 \cdot 10^{-6}$ (with a maximum of $1.6 \cdot 10^{-4}$ ), while the regulation imposes $2 \cdot 10^{-4}$. Also, the value of $0.25 \%$ in a design life of 50 years $\left(5 \cdot 10^{-5}\right.$ annually), as proposed in Silva et al. (2016), was in some cases exceeded. Judd and Charney (2014) state that "the assumed ASCE 7-10 fragility curve is conservative" and that "the conditional probability of collapse may exceed $10 \% "$.

In Vacareanu et al. (2017) the proposed values of Luco et al. (2007) and Silva et al. (2016) are tested for Romania. Compared to previous uniform hazard maps, the risk distribution changes significantly when targeting uniform risk. Vacareanu et al. (2017) calculate the ratios between the design PGA for a mean return period of 475 years and those resulting from risk targeting for $Y=2 \cdot 10^{-4}, \beta=0.8$ and $X=0.1$ and 0.001 . For the lower $X$, the ratios were below 0.6 whilst for the higher $\mathrm{X}$ they were larger than 1.0. Finally, considering two mean return periods, 475 and 2475 years, new risk maps are derived using $X=0.1$ and 0.001 . Based on the distribution of risk over the country, they conclude that using $X=$ 0.001, as proposed in Silva et al. (2016), leads to a less realistic distribution of Y.

Following US practice, the philosophy of risk targeting has been followed by the new Indonesian Earthquake Resistance Building Code SNI 1726-2012. By setting a target of $1 \%$ for the probability of collapse in 50 years, this code maps risk-targeted spectral response accelerations for $0.2 \mathrm{~s}$ and $1.0 \mathrm{~s}$. The generic fragility curves follow a lognormal distribution with $X=0.1$. Considering the material properties and human-related parameters representative of the broader area of Indonesia, Sengara et al. (2016) report values of $\beta$ around 0.7, which is adopted by SNI 1726-2012.

\section{Outstanding issues and possible paths forward}

As can be seen by Section 2 there is a rapidly increasing number of studies that have attempted to apply the risk-targeting approach to different areas or sought to constrain the various inputs upon which this technique relies. Despite these many studies a number of problems remain, which we highlight in this section along with a brief discussion of potential solutions.

As noted above, when evaluating the risk integral, ground motions for very low probabilities of exceedance sometimes need to be estimated. A power-law extrapolation appears to work well for most examples we have studied to date. Further research on the 
technicalities of the calculations, however, needs to be conducted to define a stable procedure that works for all possible inputs.

Targeting a non-zero value of collapse risk accepts that some buildings will collapse (potentially leading to human casualties) in earthquakes, even when they are designed in compliance with the building code. From a moral point of view this is problematic and it leads to the difficulty of trying to define what risk is "acceptable". One potential solution to this is to estimate an upper bound on the risk that has been "accepted" historically based on the levels of observed damage in previous earthquakes, as attempted by Labbé (2010). This "risk" is an upper bound, as generally after every damaging earthquake the population lament the damage that occurred. In the following section (3.1), some preliminary assessments using this technique are presented. Another potential solution to this problem is to target a damage state that is less severe than collapse, for example structural yielding. Targeting this limit state is less morally problematic and the level of acceptable risk in this context could be defined using, for example, cost-benefit analysis based on the cost of reducing the risk further (perhaps adopting an ALARP "as low as reasonably practicable" philosophy). This choice also has other benefits, e.g. it is generally easier to assess in numerical modelling when a structure yields rather than when it collapses.

Once the targeted risk is chosen, unless great changes to the accelerations currently used for design are accepted by practicing engineers, the probability of collapse at the design acceleration is automatically implied, as shown by Figure 3 of Douglas et al. (2013). Here there is a trilemma: any two out of the three input parameters, design IM, X and Y, can be chosen independently but not all three.

To make this point clearer, we can use the work of Žižmond and Dolšek (2017). In their article, they follow a risk-targeting approach for the derivation of the $\mathrm{q}$ factor for use in force-based design using Eurocode 8 (CEN, 2004b). In equation 4 of that paper an analytical formula is presented for the mean acceleration of the risk-targeted lognormal fragility curve, $\mu$. Adapting it to our nomenclature and recalling that our design acceleration $\mathrm{a}_{\mathrm{g}}$ implies a probability of collapse of $\mathrm{X}$, we have the following equations, which show that the various input parameters are connected:

$$
\begin{aligned}
& \mu=\left(\frac{k_{0} \cdot e^{\frac{k^{2} \cdot \beta^{2}}{2}}}{Y}\right)^{\frac{1}{k}} \\
& a_{g}=\operatorname{lognormal}^{-1}(X, \mu, \beta)
\end{aligned}
$$

where $a_{g}$ is the risk-targeted design acceleration and $k_{0}, k$ are parameters that define the idealized hazard curve. The solution to this potential problem is to check all three values are physically reasonable. This trilemma may be the reason for the apparently high target collapse probabilities (Y) used by Luco et al. (2007), as they were forced to adopt them once $\mathrm{X}$ had been defined and they did not want the design IM to change greatly from the previous code.

There is a need to derive fragility curves for a wide variety of code-designed structures with different geometries and materials. Previous studies have adopted generic fragility curves that scale constantly with the design acceleration so that the iterative procedure used to converge to the targeted risk is simple. As shown by Figure 3 of Ulrich et al. (2014b), however, this desired feature appears not to be true following current design 
practice, as they were not created with risk targeting in mind. It is possible, however, to generate a suite of fragility curves for all potential design accelerations and then to use the appropriate ones when iterating to find the actual design acceleration for a location.

Two issues concerning the used fragility functions are: what value of $\beta$ to use and, indeed, whether the lognormal distribution should continue to be used at all? Fragility curves that are used within the risk targeting calculations can imply very strong buildings (e.g. Table 1 of Douglas et al., 2013) as well as non-negligible chances of collapse for very low ground accelerations. This is a consequence of the high values of $\beta$ that need to be used to account for different types of structures of varying geometries. Two solutions to this problem are: a) adopt a different functional form for the fragility curve that equals zero for low ground accelerations and unity for very high accelerations, or b) move from generic fragility curves for all types and geometries to a curve covering only a small set of structures. The second of these changes would mean a change of philosophy of design codes to being associated with a single map giving the design accelerations for all structures to potentially many maps giving design accelerations for different structural types and geometries. This additional complexity, however, appears to be necessary if the risk-targeting approach is to imply physically realistic buildings and levels of risk.

\subsection{Assessing risk using earthquake damage databases}

In this section, we use field observations of building damage from recent earthquakes and an empirical Fermi-type approach to estimate an upper bound on the "acceptable" probability of collapse (Y) discussed above. In particular, the number of RC buildings that collapsed due to earthquakes during recent time periods in Italy and Greece are used to estimate the observed annual collapse rate.

The technique relies on the ratio of the total number of observed cases of a given damage level in a given period of time to the total number of buildings that could have been affected by earthquakes, which is then normalized to give an annual rate. Estimating both of these totals for a given country requires: a) post-earthquake field mission reports that provide the number of cases of damage and $b$ ) building census data indicating how many structures were present when the earthquake occurred.

There are a number of difficulties and uncertainties in applying this approach. For example, in some reports the number of collapses of RC buildings is combined with the number of collapses of other structural types, e.g. masonry. In others only a general "damage" category is used without specifying, for example, the number of collapses or partial collapses. Sometimes the focus of post-earthquake field missions is on estimating the number of casualties and not on collecting accurate building damage statistics. Also damage records may be incomplete, either by not including all damaging earthquakes during a time period or by not totalling all incidences of damage for a given earthquake (e.g. damage within cities but not rural areas). For example, Colombi et al. (2008), when deriving empirical vulnerability curves from Italian data, state that roughly half of the available observations cannot be used because of a lack of information on the structural type and level of damage. In addition, when combining data from different databases it is necessary to assume equivalence between various damage scales (or convert between scales). Finally (and probably most important), the sample sizes available are small, both in terms of the number of collapsed buildings and the small number of possible earthquake scenarios (locations and magnitudes) that have been sampled during the time period 
considered, which is relatively short given the recurrence interval of large earthquakes. Therefore, the annual collapse rates estimated here should be considered very rough.

We conduct a preliminary analysis for Italy and Greece, for which the earthquake damage databases are roughly complete in recent years and easily accessible, and for a combined "total or partial collapse" damage state for RC buildings. It would be relatively simple to conduct such an analysis to other developed countries, such as the USA and Japan.

The Cambridge Earthquake Impact Database (CEQID) (http://www.ceqid.org/CEQID/Home.aspx) reports the number of RC building collapses in Italian earthquakes from 1980 to 2009 inclusive (30 years) as: Irpinia 1980 (58 buildings), Eastern Sicily 1990 (3), Umbria-Marche 1997 (49), Umbria-Marche 1998 (0), Pollino 1998 (9), Molise 2002 (29) and L'Aquila 2009 (57), giving a total of 205 total or partial collapses. Colombi et al. (2008) gives an estimate of 842 collapses for almost the same period range, thereby demonstrating large uncertainty in this total.

Next it is necessary to estimate the total number of RC buildings in Italy. EPISCOPE (2014) estimates that $24.7 \%$ of Italian residential buildings are of RC and Istat (2011, http://dati-censimentopopolazione.istat.it) states that there were 14,452,680 buildings in Italy of which $12,187,698$ are residential. Therefore, it can be estimated that there are roughly 3.5 million $\mathrm{RC}$ buildings in total of which about 3 million are residential. We assume that this total has not changed over the 30 years covered by the collapse database, which given the slow population growth of Italy could be thought a reasonable assumption.

Dividing the total number of collapsed buildings by the building population and the number of years gives an estimate of the collapse rate. Using the two estimates of 205 and 842 in 30 and 23 years, respectively, and 3 or 3.5 million buildings (depending on whether the database covers all buildings or only residential) gives annual collapse rates of between $2 \cdot 10^{-6}$ and $1 \cdot 10^{-5}$, which is much lower than some of the probabilities assumed in previous risk-targeting exercises (e.g. Luco et al., 2007).

For the period 1978 to 2003 inclusive the following RC building collapses due to earthquakes in Greece have been reported: Thessaloniki 1978 (4 buildings) (CEQID), Gulf of Corinth 1981 (15) (Carydis et al., 1982), Kalamata 1986 (5), Aigion 1995 (1), Athens 1999 (69) (CEQID) and Lefkada 2003 (0) (Karababa and Pomonis, 2011), giving a total of 94 total or partial collapses. Using information from the Greek statistical service (http://www.statistics.gr) and the TABULA project (www.building-typology.eu) for the total number of RC buildings in Greece, and assuming that the building total remained constant, leads to estimates of the collapse rate between $1 \cdot 10^{-6}$ and $2 \cdot 10^{-6}$, again much lower than some assumed probabilities for the targeted risk.

The accuracy of these estimates could be improved by using a more complete database both for the numerator (the damage) and the denominator (the number of buildings at risk) and by extending the time period covered so that more potential earthquake scenarios are considered. Nevertheless, such an analysis is constrained by the long recurrence intervals of damaging earthquakes, which means that the assessed rates will always be associated with large uncertainties. In addition, variations due to building type (e.g. masonry versus reinforced concrete), location (e.g. developed versus less-developed countries) and damage level (e.g. collapse versus yield) could be studied as well. 
The same procedure was repeated for the same two countries considering a different damage state. A broader class was defined to represent 'yield', as considered by Ulrich et al. (2014), which includes the total number of RC buildings that are neither not-damaged nor collapsed (partially or in total). The same limitations discussed before are also the case here. In addition, complete data were available for a shorter period of 18 years for Greece (but still 30 years for Italy). With these assumptions, the annual percentage of yield is found equal to $3 \cdot 10^{-5}$ for Italy and $1 \cdot 10^{-4}$ for Greece. Apart from providing useful constraints on the inputs to risk-targeting this type of analysis could have other benefits as well. Firstly, they would provide an observational-based assessment of earthquake risk that can be compared to estimates from computer modelling, which require a large number of inputs and can be opaque to decision makers. If there are large differences in these estimates it may indicate that the computer models require calibration. Secondly, these estimates will enable differences in earthquake risk levels between countries to be judged more easily and used to understand what the impact of reducing risk could be in terms of the average number of buildings that could collapse per year, for example.

\section{Conclusions}

Crowley et al. (2013) propose that 'Risk-targeted seismic design actions' should be considered for future versions of the Eurocodes. A call echoed by Formichi et al. (2016) in a report on the background and application of Eurocodes, published on behalf of the European Commission. This report also proposes that changes made in other international seismic design codes should be considered when updating the Eurocodes. It is, therefore, clear that application of the risk-targeting approach is being seriously discussed in Europe. In consequence, additional research effort to this end would provide valuable input for the development of risk-targeted design maps for new buildings in Europe.

In this brief article, we have highlighted the critical issues that we believe need to be solved before the risk-targeting approach for the development of seismic design codes can be employed in practice. Some of these (e.g. development of appropriate fragility functions) solely require engineering calculations but others (e.g. choice of the acceptable level of risk) need input from other domains, including decision makers. In the coming years we plan to tackle these issues, particularly with respect to future Eurocodes.

\section{Acknowledgements}

The second author of this article is undertaking a $\mathrm{PhD}$ funded by a University of Strathclyde "Engineering The Future" studentship, for which we are grateful. We thank Florin Pavel for sharing the submitted version of Vacareanu et al. (2017). We thank Roberto Paolucci for discussions concerning empirical estimates of collapse risk.

\section{References}

Allen TI, Adams J, Halchuk S (2015) The seismic hazard model for Canada: Past, present and future. Proceedings of the Tenth Pacific Conference on Earthquake Engineering Building an EarthquakeResilient Pacific, Sydney, Australia. Paper number 100.

ASCE (2005) Seismic Design Criteria for Structures, Systems and Components in Nuclear Facilities. American Society of Civil Engineers, ASCE Standard 43-05.

ASCE (2010) Minimum Design Loads for Buildings and Other Structures, ASCE Standard 7-10. American Society of Civil Engineers, Reston, VA.Braverman JI, Xu J, Ellingwood BR., Costantino CJ, Morante RJ, Hofmayer CH (2007) Evaluation of the Seismic Design Criteria in 
ASCE / SEI Standard 43-05 for Application to Nuclear Power Plants. Agencywide Documents Access and Management System (ADAMS) - USNRC.

Carydis PG, Tilford NR, Brandow GE, Jirsa JO (1982) The central Greece earthquakes of FebruaryMarch 1981, Report No. CETS-CND-018 of the Earthquake Engineering Research Institute, Berkeley, CA, National Academy Press, Washington, DC.

CEN (2004a) EN 1992-1-1:2004 Eurocode 2: Design of concrete structures - Part 1-1: General rules and rules for buildings, European Committee for Standardization, Brussels.

CEN (2004b) EN 1998-1:2004 Eurocode 8: Design of structures for earthquake resistance - Part 1: General rules, seismic actions and rules for buildings, European Committee for Standardization, Brussels.

Colombi, M, Borzi B, Crowley H, Onida M, Meroni F, Pinho R (2008), Deriving vulnerability curves using Italian earthquake damage data, Bulletin of Earthquake Engineering, 6(3), 485-504, doi: 10.1007/s10518-008-9073-6.

Crowley H, Weatherill G, Pinho R (2013) Suggestions for Updates to the European Seismic Design Regulations. SHARE Deliverable 2.6. Universita degli Studi di Pavia.

Douglas J, Ulrich T, Negulescu C (2013) Risk-targeted seismic design maps for mainland France. Natural Hazards 65(3): 1999-2013.

EPISCOPE (2014) Inclusion of new buildings in residential building typologies: Steps towards NZEBs exemplified for different European countries, EPISCOPE Synthesis Report no. 1 (Deliverable D2.4). Contract No: IEE/12/695/SI2.644739. ISBN 978-3-941140-42-4.

Fajfar P, Dolšek M (2012) A practice-oriented estimation of the failure probability of building structures. Earthquake Engineering and Structural Dynamics 41: 531-547.

FEMA (2009) NEHRP Recommended Seismic Provisions for New Buildings and Other Structures (FEMA P750). Federal Emergency Management Agency.

Formichi P, Danciu L, Akkar S, Kale O, Malakatas N, Croce P, Nikolov D, Gocheva A, Luechinger P, Fardis M, Yakut A, Apostolska R, Sousa ML, Dimova S, Pinto A (2016) Eurocodes: background and applications. Elaboration of maps for climatic and seismic actions for structural design with the Eurocodes. EUR, doi: 10.2788/534912.

Goulet C, Haselton C, Mitrani-Reiser J, Beck J, Deierlein G, Porter K, Stewart, J (2007) Evaluation of the seismic performance of a code-conforming reinforced-concrete frame building - from seismic hazard to collapse safety and economic losses. Earthquake Engineering and Structural Dynamics 36: 1973-1997.

ICC IBC, (2003) International Building Code (IBC), International Code Council (ICC), IL, USA

ICC IBC (2012) International Building Code (IBC), International Code Council (ICC), IL, USA.

Iervolino I, Spillatura A, Bazzurro P (2017) RINTC project: Assessing the (implicit) seismic risk of code-conforming structures in Italy. COMPDYN 2017, 6th ECCOMAS Thematic Conference on Computational Methods in Structural Dynamics and Earthquake Engineering, M. Papadrakakis, M. Fragiadakis (eds.), Rhodes, Greece.

Judd JP, Charney FA (2014) Earthquake risk analysis of structures. In: Proceedings of the 9th International Conference on Structural Dynamics, EURODYN 2014, 2929-2938.

Karababa FS, Pomonis A (2011) Damage data analysis and vulnerability estimation following the August 14, 2003 Lefkada Island, Greece, earthquake, Bulletin of Earthquake Engineering 9:10151046, doi: 10.1007/s10518-010-9231-5.

Kennedy RP (2011) Performance-goal based (risk informed) approach for establishing the SSE site specific response spectrum for future nuclear power plants. Nuclear Engineering and Design, 241:648-656.

Labbé PB (2010) PSHA outputs versus historical seismicity: Example of France. In: Proceedings of Fourteenth European Conference on Earthquake Engineering.

Liel AB, Luco N, Raghunandan M, Champion, CP (2015) Modifications to risk-targeted seismic design maps for subduction and near-fault hazards. In: 12th International Conference on Applications of Statistics and Probability in Civil Engineering, ICASP12, Vancouver, Canada.

Luco N, Ellingwood BR, Hamburger RO, Hooper JD, Kimball JK, Kircher CA (2007) Risk-targeted versus current seismic design maps for the conterminous United States. In: SEAOC 2007 convention proceedings.

Martins L, Silva V, Crowley H, Bazzurro P, Marques M (2015) Investigation of structural fragility for risk-targeted hazard assessment. In: 12th International Conference on Applications of Statistics and Probability in Civil Engineering, ICASP12, Vancouver, Canada.

Ramirez CM, Liel AB, Mitrani-Reiser J, Haselton CB, Spear AD, Steiner J, Deierlein GG, Miranda E (2012) Expected earthquake damage and repair costs in reinforced concrete frame buildings. Earthquake Engineering and Structural Dynamics, 41: 1455-1475. 
RELUIS and EUCENTRE (2014-2018) Research Project DPC - RELUIS/EUCENTRE, Technical Report and Deliverables.

Sengara IW, Sidi ID, Mulia A, Muhammad A, Daniel H (2016) Development of risk coefficient for input to new Indonesian seismic building codes. Journal of Engineering and Technological Sciences, 48(1): 49-65.

Silva V, Crowley H, Bazzurro P (2016) Exploring risk-targeted hazard maps for Europe, Earthquake Spectra, 32(2):1165-1186.

SNI (2012) Tata cara perencanaan ketahanan gempa untuk struktur bangunan gedung dan non gedung. Badan Standardisasi Nasional, ICS 91.120.25;91.080.01. Report 1726:2012. In Indonesian.

Tsang HH, Wenzel F (2016) Setting structural safety requirement for controlling earthquake mortality risk. Safety Science, 86: 174-183.

Tsang HH, Lumantarna E, Lam NTK, Wilson JL, Gad E (2017) Annualised collapse risk of soft-storey building with precast RC columns in Australia. Mechanics of Structures and Materials: Advancements and Challenges, 1681-1686.

Ulrich T, Negulescu C, Douglas J (2014a) Fragility curves for risk-targeted seismic design maps. Bulletin of Earthquake Engineering 12(4): 1479-1491.

Ulrich T, Douglas J, Negulescu C. (2014b) Seismic risk maps for Eurocode-8 designed buildings, In: Proceedings of the Second European Conference on Earthquake Engineering and Seismology.

United States Nuclear Regulatory Commission (2007) A performance-based approach to define the site specific earthquake ground motion. Technical report 1.208.

Vacareanu R, Pavel F, Craciun I, Coliba V, Arion C, Aldea A, Neagu C (2017) Risk-targeted maps for Romania. Journal of Seismology, submitted.

Žižmond J, Dolšek M (2017) The formulation of risk-targeted behaviour factor and its application to reinforced concrete buildings, Proceedings of the $16^{\text {th }}$ World Conference on Earthquake Engineering, Santiago, Chile, 9-13 January. Paper no. 1659. 